\title{
Perancangan Sistem Pendaftaran Siswa Baru Labschool Jakarta Menggunakan Java Netbean
}

\author{
Ilham Wijiyatno ${ }^{1)}$ \\ 1) Mahasiswa Prodi Informatika, Fakultas Teknik dan Ilmu Komputer, Universitas Indraprasta PGRI \\ Email: ilhamw02@gmail.com
}

\begin{abstract}
Abstrak
Tujuan perancangan aplikasi system pendaftaran siswa baru ini adalah agar Sistem Pendaftaran Siswa Baru Labschool Jakarta Menggunakan Java Netbean menjadi terkomputerisasi dan menyediakan interface yang dapat mempermudah tugas dalam mengolah data administrasi pendaftaran siswa-siswi baru Labschool Jakarta, dan agar pekerjaan dapat terselesaikan dengan cepat, tepat, akurat guna mengefisiensikan waktu. Metode yang digunakan dalam penelitian ini adalah menggunakan metode grounded research yaitu metodologi penelitian kualitatif yang menekankan penemuan teori dari data observasi empiric dilapangan dengan metode induktif (menemukan teori dari sejumlah data). Dalam penelitian jenis ini, peneliti langsung dating kelapangan tanpa membawa rancangan konseptual, proposisi, atau teori-teori tertentu seperti yang dilakukan pada penelitian kualitatif pada umumnya. Kata Kunci: Aplikasi, Pendaftaran, Siswa Baru
\end{abstract}

\begin{abstract}
The purpose of designing this new student registration system application is for the Labschool Jakarta New Student Registration System to use Java Netbean to be computerized and provide an interface that can simplify the task of processing administrative data registration new Labschool Jakarta students, and so that work can be completed quickly, precisely, accurate in order to make time efficient. The method used in this study is to use the grounded research method, which is a qualitative research methodology that emphasizes theoretical findings from empiric observational data in the field with inductive methods (finding theories from a number of data). In this type of research, researchers directly dating spaciousness without carrying conceptual designs, propositions, or certain theories as is done in qualitative research in general. Keywords: Application, Registration, New Students.

Keyword : Application, Registration, New Student
\end{abstract}




\section{PENDAHULUAN}

A. Latar Belakang

Sistem informasi dan teknologi komputer berkembang sangat pesat sejalan dengan semakin besarnya kebutuhan terhadap informasi. Kemajuan teknologi menuntut segala sesuatu pekerjaan manusia yang masih manual dan kurang efisien dapat dilakukan dengan teknologi yang maju pula. Pekerjaan yang dilakukan secara manual sebaiknya lebih ditingkatkan lagi menggunakan sistem komputerisasi agar dapat membantu mempercepat menyelesaikan pekerjaan yang semula masih dilakukan secara manual.

Pengaruh yang paling nyata terlihat pada terjadinya perubahan yang mendasar terhadap cara orang melakukan komputasi, terutama yang di implementasikan dalam bisnis dan kehidupan kita sehari-hari. Teknologi informasi dan komputer akan membuat taraf kehidupan manusia meningkat pesat. Berbagai kendala dapat dipecahkan dengan lebih mudah dan efisien. Kendala informasi misalnya, dapat dipecahkan dengan teknologi informasi berupa internet.

Perubahan dan dinamika masyarakat yang semakin cepat seiring dengan perkembangan zaman dan teknologi sehingga memerlukan kualitas informasi yang akurat, cepat, dan tepat. Teknologi informasi adalah salah satu contoh produk teknologi yang berkembang pesat yang dapat membantu manusia dalam mengolah data serta menyajikan sebuah informasi yang berkualitas.

Labschool adalah sekolah yang didirikan tahun 1968, sebuah sekolah yang dimaksudkan sebagai sekolah laboratorium IKIP Jakarta. Sekolah ini digunakan untuk praktik ajar, penelitian pendidikan, dan inovasi pendidikan. Sebagai gantinya, sekolah ini berganti nama Proyek TPK (Comprehensive School). Sekolah ini mengemban tugas sebagai Tempat Pembinaan Keterampilan (Proyek TPK) dari Departemen Pendidikan dan Kebudayaan. Proyek TPK bertujuan untuk mencobakan ide-ide baru dalam bidang pendidikan. Labschool merupakan sekolah yang mempersiapkan calon pemimpin masa depan yang bertakwa, berintregritas tinggi, berdaya juang kuat, berkepribadian utuh, berbudi pekerti luhur, mandiri, serta mempunyai kemampuan intelektual yang tinggi.

Pendaftaran siswa baru pada labschool ada 4 jenjang pendaftaran yang dapat dipilih sesuai dengan tingkatan yang dibutuhkan, yaitu TK, SD, SMP dan SMA. Bagi siswa yang ingin mendaftar dapat mengisi formulir pendaftaran yang disediakan oleh bagian administrasi, kemudian calon siswa akan melaksanakan tes seleksi dan tes kesehatan, bila calon siswa dinyatakan lulus, kemudian calon siswa dapat melakukan daftar ulang dan verifikasi nilai rapot, hingga akhirnya calon siswa tersebut dinyatakan lolos sebagai siswa labschool. Hanya sayangnya proses input data pendaftaran calon siswa yang saat ini lakukan masih manual sehingga terkadang terjadi kesalahan saat penulisan atau hilang data dikarenakan data yang disimpan terselip, dan membutuhkan waktu yang cukup lama untuk mencari data calon siswa yang dibutuhkan.

Berdasarkan latar belakang di atas, penulis menyusun sebuah skripsi untuk perancangan sebuah sistem informasi labschool yang terkomputerisasi oleh suatu program berbasis desktop yang berjudul "Perancangan Sistem Pendaftaran Siswa Baru Labschool Jakarta Menggunakan Java Netbean". 


\section{B. Identifikasi Masalah}

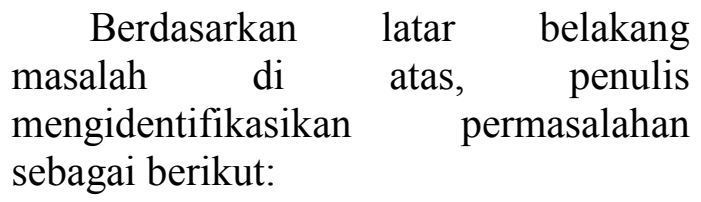

1) Sistem pengolahan data pendaftaran pada labschool Jakarta membutuhkan waktu yang cukup lama.

2) Sistem pengolahan data pendaftaran pada labschool Jakarta masih belum terkomputerisasi.

3) Proses pencarian dan pengolahan data pendaftaran masih memakan waktu yang cukup lama dan rentan terjadi kesalahan atau kehilangan data.

\section{Batasan Masalah}

Permasalahan dibatasi pada pembuatan sistem informasi pengolahan data pendaftaran, khususnya pada pengolahan data calon siswa yang melakukan pendaftaran jenjang SD pada labschool Jakarta.

\section{LANDASAN TEORI}

\section{A. Pengertian Perancangan}

Menurut Kusrini dkk (2007:79) "Perancangan adalah Proses pengembangan spesifikasi sistem baru berdasarkan rekomendasi analisis sistem".[1]

Menurut Roger S. Pressman (2010:291) "Perancangan yang sesungguhnya merupakan suatu aktivitas rekayasa perangkat lunak yang dimaksud untuk membuat keputusankeputusan utama seringkali bersifat struktural".[2]

\section{B. Pengertian Sistem}

Menurut Kusrini dkk (2007:11) "Sistem merupakan kumpulan elemen yang saling berkaitan yang bertanggung jawab memproses masukan (input) sehingga menghasilkan keluaran (output)". [3]

Menurut Kristanto (2012:6) "Sistem adalah jaringan kerja dari prosedur - prosedur yang saling berhubungan, berkumpul bersama sama untuk melakukan suatu kegiatan atau menyelesaikan suatu sasaran tertentu".[4]

\section{Pengertian Informasi}

Menurut Jogiyanto H.M (2010:3) "Informasi (information) adalah hasil dari kegiatan pengolahan data yang memberikan bentuk yang lebih berarti dari suatu kejadian".[5]

\section{METODE PENELITIAN \\ A. Metode Penelitian}

Metode yang digunakan dalam penelitian ini adalah menggunakan metode analisis deskriptif analisis dengan pendekatan kuantitatif, yaitu penelitian yang kemudian di olah dan di analisis untuk diambil kesimpulan. Artinya, penelitian yang dilakukan adalah penelitian yang menekankan pada perancangan sistem informasi pendaftaran data calon siswa baru.

\section{B. Metode Pengumpulan Data}

Metode pengumpulan data yang dilakukan untuk mendapatkan data-data serta informasi untuk mendukung penyempurnaan hasil dari penelitian ini antara lain :

\section{1) Studi Pustaka}

Pengumpulan data dan informasi dari kutipan-kutipan, bukubuku, peraturan perundangundangan, serta hasil laporan dan bahan lainnya yang berkaitan dengan 
penelitian ini. Dari bahan-bahan tersebut diambil teori-teori yang dapat dijadikan landasan untuk menganalisa masalah yang ditemukan dalam penelitian.

\section{2) Studi Lapangan}

\section{a. Wawancara}

Untuk memperoleh data dan atau informasi yang lebih rinci untuk melengkapi data observasi, peneliti dapat melakukan wawancara. Wawancara ditujukan kepada pimpinan labschool Jakarta dan karyawan labschool Jakarta, wawancara tersebut mengenai hal-hal yang berhubungan dengan Perancangan Sistem Pendaftaran Siswa Baru Labschool Jakarta Menggunakan Java Netbean. Hasil wawancara merupakan kelengkapan data yang bertujuan sebagai pertimbangan didalam mengambil kesimpulan penelitian. Adapun data yang diperlukan antara lain :

1) Profil atau sejarah labschool Jakarta.

2) Bagaimana sistem pengolahan data yang sedang berlangsung?

3) Apa saja kendala atau masalah yang sering dihadapi oleh karyawan labschool Jakarta selama ini ?

\section{b. Observasi}

Observasi merupakan salah satu cara mengumpulkan data yang diperlukan dengan cara melakukan pengamatan dan meneliti secara langsung kegiatan yang akan diselidiki oleh penulis.
4. HASIL DAN PEMBAHASAN

A. Diagram Alir Data

1) Diagram Konteks

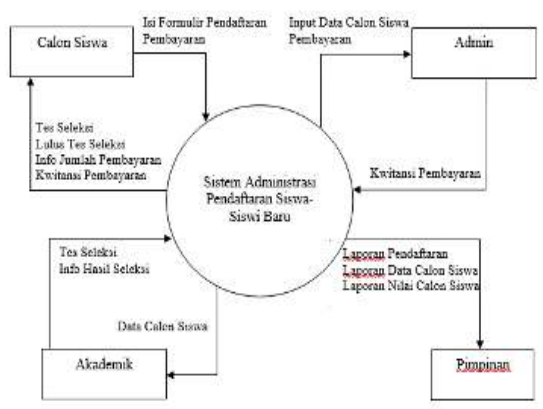

Gambar 1. Diagram Konteks Sistem Berjalan

2) Diagram Nol

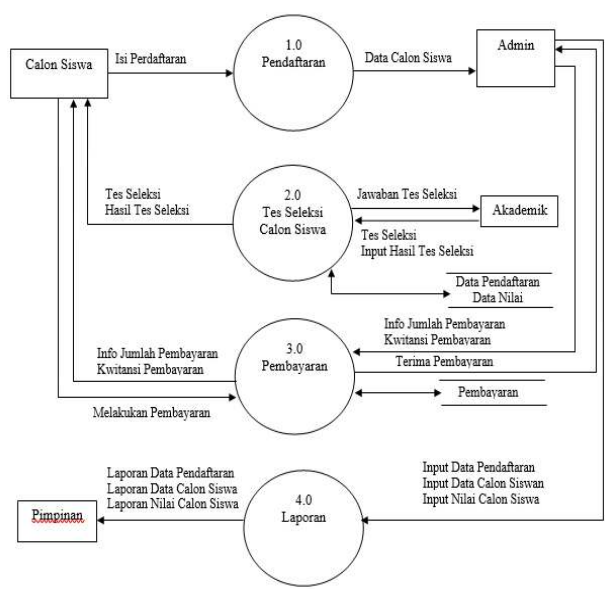

Gambar 2. Diagram Nol Sistem Berjalan

3) Diagram Rinci

a.Diagram Rinci 1 Proses 1.1

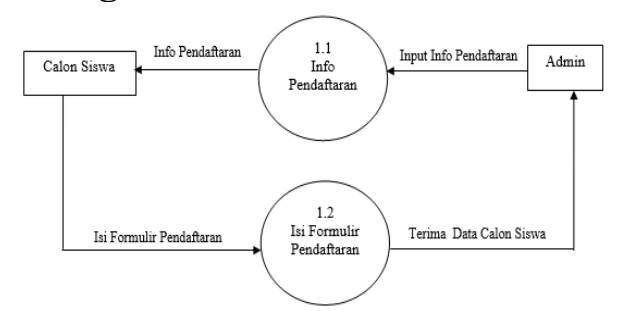

Gambar 3. Diagram Rinci level 1 Proses 1.1

\section{b. Diagram Rinci Proses 2.1}

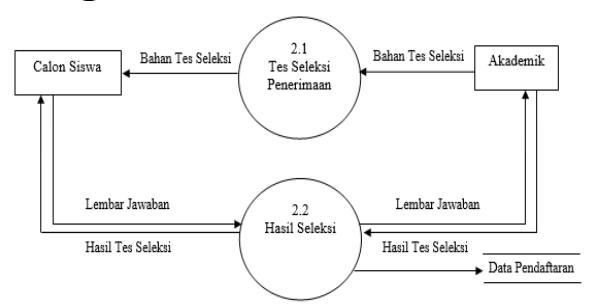

Gambar 4. Diagram Rinci level 2 Proses 2.1 


\section{c. Diagram Rinci Proses 3.1}

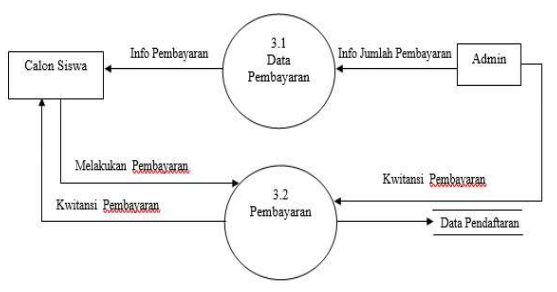

Gambar 5. Diagram Rinci level 1 Proses 3.1

4) Diagram Rinci proses 4.1

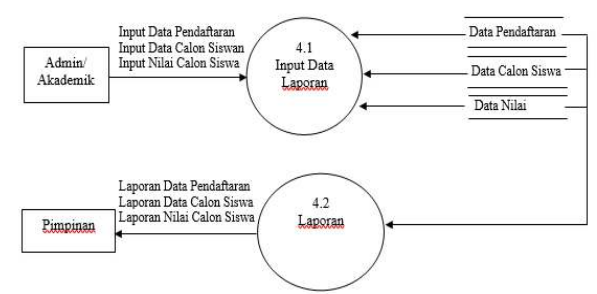

Gambar 6. Diagram Rinci level 2 Proses 4.1

\section{B. Entity Relationship Diagram}

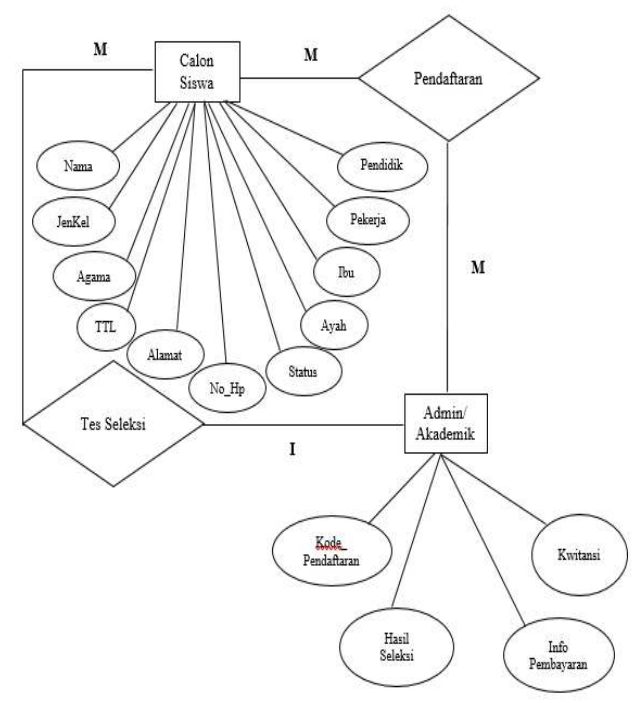

Gambar 7. Entity Relationship Diagram

C. Tampilan Layar, Tampilan Form Masukan (Input) dan Tampilan Keluaran (Output)

1) Tampilan Layar
a. Form Login

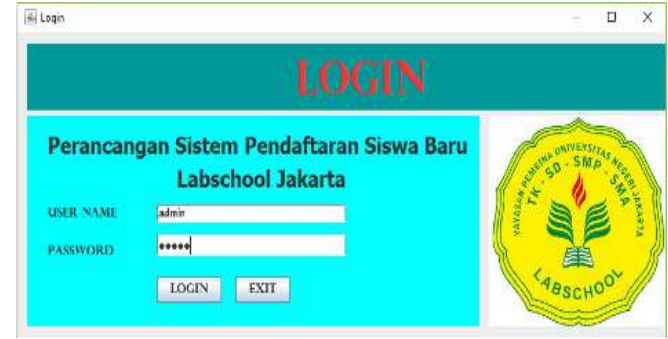

Gambar 8. Form Login

\section{b. Tampilan Home}

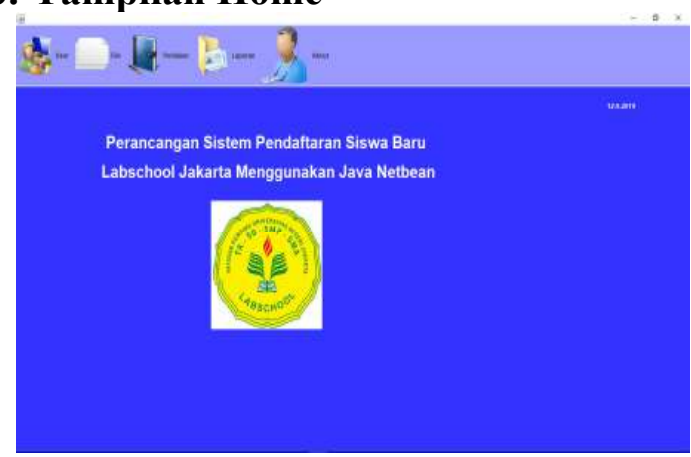

Gambar 9. Form Home

2) Tampilan Menu Pegawai

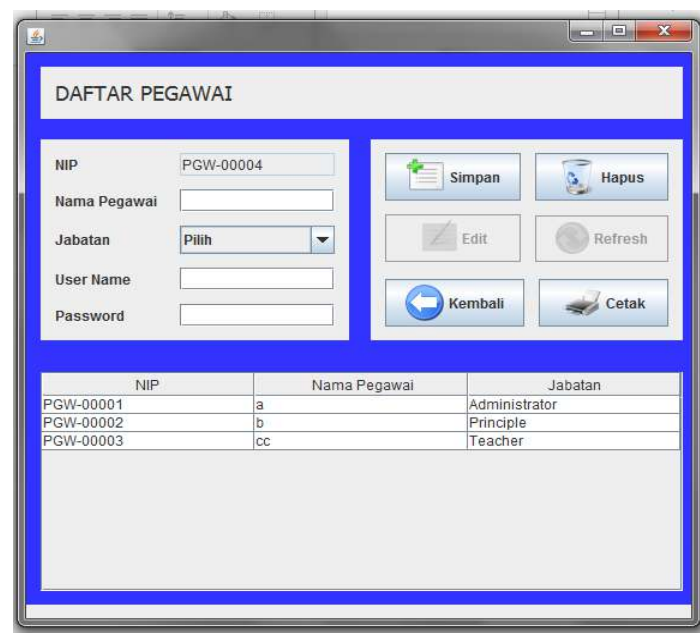

Gambar 10. Tampilan Menu Pegawai 
3) Tampilan Menu Pendaftaran

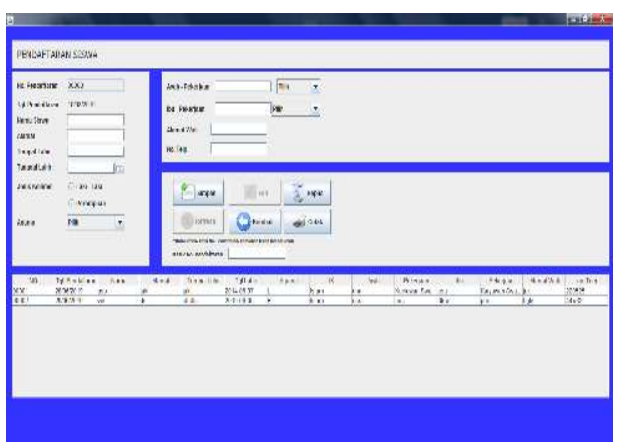

Gambar 11. Tampilan Menu Pendaftaran

4) Tampilan Menu Penilaian Calon Siswa

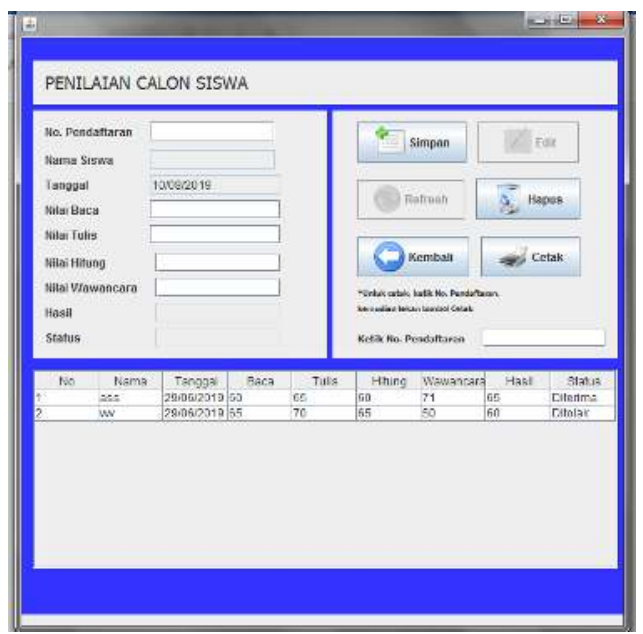

Gambar 12. Tampilan Menu Penilaian

\section{5) Tampilan Menu Laporan Pendaftaran Calon Siswa}

\section{LABSCHOOL}

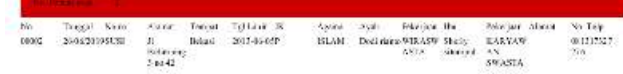
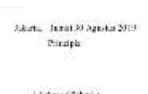

Gambar 13. Tampilan Menu Laporan Pendaftaran

6) Tampilan Keluaran (output)

a. Laporan Data Siswa
LABSCHOOL

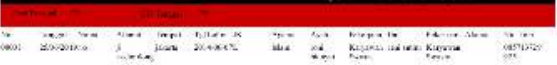

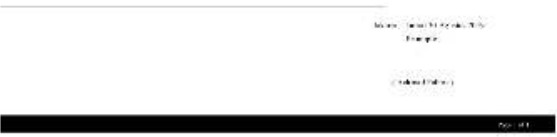

Gambar 14. Laporan data siswa

b. Laporan Data Nilai Hasil Calon Siswa

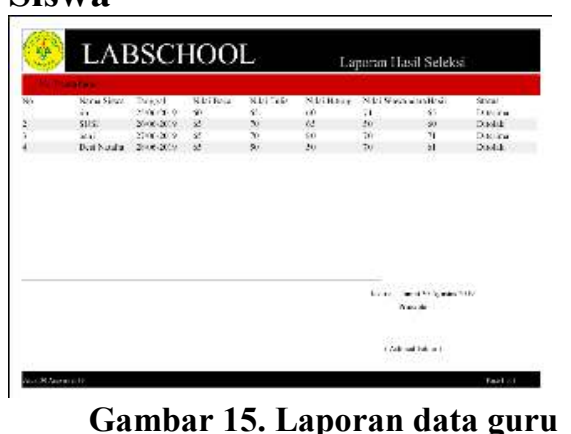

Gambar 17. Laporan Data saldo Keluar

\section{A. SIMPULAN}

\section{SIMPULAN DAN SARAN}

Berdasarkan hasil penelitian pada Perancangan Sistem Pendaftaran Siswa Baru Labshcool Jakarta Menggunakan Java Netbean dalam tugas akhir ini, maka penulis dapat membuat sebuah kesimpulan antara lain:

1. Sistem Administrasi Pendaftaran Siswa Baru Labshcool Jakarta ini diharapkan dapat mempermudah dan membantu karyawan Labshcool Jakarta dalam melakukan pengolahan data siswa-siswi baru Labshcool Jakarta.

2. Perancangan Sistem Pendaftaran Siswa Baru Labshcool Jakarta Menggunakan Java Netbean ini diharapkan dapat mempermudah dan membantu para orang tua dan calon siswa dalam melakukan pendaftaran 
dan melihat hasil pengumuman penerimaan pada Labshcool Jakarta.

3. Memberikan pelayanan informasi yang efektif dan efisien kepada karyawan dengan menggunakan media komputer yang dapat diterapkan melalui sebuah aplikasi yang dirancang sedemikian rupa agar sesuai dengan kebutuhan informasi bagi karyawan

4. Perancangan Sistem Pendaftaran Siswa Baru Labshcool Jakarta Menggunakan Java Netbean ini dapat dijalankan kapan saja saat

5. admin ingin melakukan pendataan atau menyerahkan laporan kepada pimpinan.

\section{B.SARAN}

Penulis menyadari bahwa aplikasi ini masih jauh dari sempurna, namun penulis mencoba membuat sebuah aplikasi yang diharapkan dapat membantu mempermudah karyawan Labshcool Jakarta dalam melakukan pengolahan data siswa-siswi baru Labshcool Jakarta. Adapun saran yang dapat penulis sampaikan untuk dipertimbangkan diantaranya:

1. Agar pengguna dapat menggunakan aplikasi ini penuh dengan tanggung jawab.

2. Aplikasi ini jauh dari sempurna maka penulis menyarankan agar halaman muka / interface dapat lebih disempurnakan lagi sehingga lenih memudahkan dan adanya penambahan tool-tool yang dapat berguna pada aplikasi ini.dalam menginput data perlu diperhatikan agar data yang sudah direkam (store) benar-benar merupakan salinan dari data sumber.

\section{DAFTAR PUSTAKA}

Buku:

[1] Aditama Roki, 2012. Sistem Informasi Akademik Kampus PHP. Yogyakarta: Lokomedia.

[2] Andi Jogiyanto, 2010. Analisis \& Desain. Yogyakarta. Andi.

[3] Arief, M.Rudianto. 2011. Pemrograman Web Dinamis Menggunakan Php dan Mysql. Yogyakarta: ANDI.

[4] Jimmy L Gaol, 2009. Sistem Informasi Manajemen. Jakarta: Grassindo.

[5] Kristanto, A. (2009). Perancangan Sistem Informasi dan Aplikasinya. Yogyakarta: Gava Media.

[6] Kusrini, 2009. Strategi Perancangan dan Pengelolaan Basis Data. Yogyakarta: Andi.

[7] Nugroho, Adi. 2009. E-commerce Informatika. Bandung. Bandung.

[8] Sugiarto, Mozes. 2009. Google Cheat. Jakarta : PT. Elex Media Komputindo.

Internet:

[1] Ade Sanjaya. Pengertian Administrasi Fungsi Tujuan Peran dan Ruang Lingkup. http://www.landasanteori.com/2015/ 07/pengertian-administrasi-fungsitujuan.html. Diakses pada tanggal 18 Juni 2019 pukul 18.53 WIB.

[2] Dunia Ilmu Komputer. Pengertian dan Fungsi PHP dalam Pemrograman. 
https://www.duniailkom.com/pengert ian-dan-fungsi-php-dalam-

pemograman-web/. Diakses pada tanggal 18 Juni 2019 pukul 17.22 WIB.

[3] Enggar Wicdho Prasetyo. Sistem Informasi Pendaftaran Calon Anggota Legislatif Pada KPU Kabupaten Kudus. http://eprints.umk.ac.id/6951/1/COV ER.pdf. Diakses pada tanggal 25 Juni 2019 pukul 17.45 WIB.

[4] Irwin Nugroho. Sistem Informasi Penerimaan Siswa Baru .http://eprints.uny.ac.id/20391/1/Irwi $\mathrm{n} \% 20$ Nugroho\%2007520244075.pdf . Diakses pada tanggal 25 Juni 2018 pukul 16.05 WIB.

[5] Kelembagaan.ristekdikti. UndangUndang Republik Indonesia Nomor 20 Tahun 2003 Tentang Tentang Sistem Pendidikan Nasional. https://kelembagaan.ristekdikti.go.id/ wpcontent/uploads/2016/08/UU_no_20 th_2003.pdf. Diakses pada tanggal 01 Agustus 2018 pukul 14.25 WIB.

\section{Jurnal dan Skripsi:}

[1] Eni Irfiani, Muhammad Encep, Rancang Bangun Sistem Informasi PPDB (Penerimaan Peserta Didik Baru) SMP Amaliah Bogor. Vol 5, pp. 10-16, ISSN: 2355-990X, eISSN: 2549-5178, Amik BSI Jakarta. 2017.

[2] Naely Farkhatin. Perancangan Sistem Informasi Penerimaan Siswa Baru SMK Nusantara Ciputat Tanggerang. Vol 5 No 2: 124-132, ISSN: 1979-276X, e-ISSN : 2502339X, Universitas Indraprasta PGRI. 2012.
[3] Satya Pamungkas. Sistem Informasi Penerimaan Siswa Baru Menggunakan Bahasa Pemrograman Java dan Database Oracle. Politeknik Negri Bengkalis. 2011.

[4] Singgih Adyanwar. Perancangan Sistem Informasi Penerimaan Siswa Baru Di SMA Negeri 2 Boyolali. Sekolah Tinggi Manajemen Informatika dan Komputer AMIKOM Yogyakarta. 2009. 